\title{
The Challenge of Recruiting Underrepresented Groups - Exploring Organizational Recruitment Practices in Sweden'
}

\section{Ali Osman ${ }^{2}$}

Associate Professor, Senior Lecturer, Stockholm University, Department of Education, Sweden

\section{Camilla Thunborg ${ }^{2}$}

Professor, Stockholm University, Department of Education, Sweden

\begin{abstract}
The aim of this article is to explore organisational recruitment practices from human resources (HR) experts' narratives and discuss the challenges of recruiting underrepresented groups in relation to these practices. From the HR experts' narratives, we identify four organisational recruitment practices: the informal, the pragmatic, the standardised and the strategic. These practices consist of, for example, 'subjective' judgements versus 'objective' criteria and are construed in relation to different rationalities, which also give rise to various dilemmas in relation to underrepresented groups. From our analysis, there seems to be a paradox between enhancing diversity and counteracting discrimination. Organisational recruitment practices that are counteracting discrimination do not necessarily enhance diversity and recruitment practices that radically work with enhancing diversity can be seen as discriminatory. We thereby draw the conclusion that there is no effective practice for the recruitment of underrepresented groups in the labour market. This is a dilemma for HR experts and a challenge for the Swedish labour market in general.
\end{abstract}

\section{KEY WORDS}

Recruitment practices / HR experts / underrepresented groups / labour market / Sweden

\section{Introduction}

his article is concerned with human resources (HR) experts' narratives on organisational recruitment practices and their logics and dilemmas in the process of recruiting underrepresented groups in the Swedish labour market. Over the last decade, the weak position of underrepresented groups at different levels in the labour market has become a subject of heated debate in Sweden. The debate generally revolves around factors that affect the macrolevel structure of employment of, for example, immigrants, their descendants, the LGBT community, etc. The disadvantaged position of underrepresented groups is explained as a consequence of either discrimination, or that immigrants lack relevant social capital, language skills, wrong job search strategies, relevant job skills, etc. (Osman; Tovatt 2013; Vesterberg 2015).

When discussing the underrepresentation of these groups at an organisational level, the recruitment process is often referred to as critically important. HR experts are often

\footnotetext{
${ }^{1}$ You can find this text and its DOI at https://tidsskrift.dk/njwls/index

${ }^{2}$ Corresponding authors: ali.osman@edu.su.se and camilla.thunborg@edu.su.se.
} 
seen as gatekeepers in the process of recruitment, so an understanding of their experience is crucial to understanding both the practice and the challenges of recruitment when it comes to underrepresented groups.

A general definition of recruitment is 'finding people with the right skills for the right positions, irrespective of their origin' (Bolander 2002; Breaugh 2000, 2008; Skorstad 2011). Research, however, shows that underrepresented groups are often disadvantaged in the process of recruitment - even though in Sweden, like all Western democratic countries, discrimination on the grounds of ethnicity, race, religion, sexuality or gender is prohibited. However, a lot of research suggests that immigrants are subjected to discrimination (Baert et al. 2015; Bursell 2007; Blommaert et al. 2014; Derous et al. 2009; Eriksson \& Lagerström 2012; Hoque \& Noon 1999; Kaplan \& Fischer 2009; McGinnity \& Lunn 2011). Similarly, other research asserts that women are professionally sidelined based on myths of motherhood and work/family balance (Stevanovic 2014; Verniers \& Vala 2018) and are discriminated against in male-dominated sectors such as science and technology, high-tech (Fernandez \& Campero 2017), engineering (Mamaril \& Royal 2008) and academia, based on gender stereotypes (Brower \& Caven 2013; Venkatesh et al. 2017). Finally, age discrimination affects both young and older people (Poulston \& Jenkins 2016; Sargeant 2010).

The recruitment of underrepresented groups is often legitimated by claiming that diverse workplaces are more creative, while others argue that it can be dysfunctional (McKay \& Avery 2005; D’Netto \& Sohal 1999; Gilbert \& Ivanevich 2000). Similarly, there are studies showing that diversity management is positively correlated with job contentment and that black and minority ethnic benefit from diversity management (Pitts 2009). For this reason, it is of interest to discuss the challenges of recruiting underrepresented groups from the perspective of HR experts.

In this article, we focus on the practice of recruitment according to the narratives of HR experts and discuss the challenges of recruiting underrepresented groups in relation to this practice. In our analysis, we use Czarniawska's (2014) concept of practice, which is defined as ongoing processes of organising, where actors coordinate their actions in everyday life and make sense of them retrospectively (Weick 1995) through their narratives, which are here seen as ongoing actions in practice. We distinguish between the logic of practice and the logic of representation to understand both the practice itself and how it is legitimated in the narratives.

The aim of the article is to explore organisational recruitment practices from HR experts' narratives and discuss the challenges of recruiting underrepresented groups in relation to these practices. The article addresses the following research questions:

1. What organisational recruitment practices can be identified from the narratives of HR experts?

2. What dilemmas concerning the recruitment of underrepresented groups are present in the narratives of HR experts?

\section{Previous research}

In this section, we present research about recruitment that focuses particularly on the selection and recruitment of a candidate that fits the job, group or organisation and how 
this can affect the recruitment of underrepresented groups. We also present some studies that examine the recruitment process from the perspective of HR experts.

In many studies, distinctions between person-organisation fit, person-group fit and person-job fit are used (e.g. Bergström 1998; Sekiguchi \& Huber 2011) to understand the decisions behind the selection of candidates for different positions. In one study, Sekiguchi and Huber (2011) show that person-organisation fit weighs more heavily for general and permanent positions, while person-job fit weighs more heavily for fixedterm contracts and knowledge-intensive positions in the labour market. Furthermore, Wolgast (2017) finds an increased focus on person-group fit (including such factors as social competence) when norms related to workforce cohesion are introduced, compared with an increased focus on person-job fit (such as job-specific skills and abilities) when fairness norms related to equal opportunity are introduced. She also finds that the norm effect is moderated by the recruiters' awareness of the applicants' ethnicity. When expecting applicants with a foreign background, the recruiter shows, for example, an increased preference for selection methods related to social competence and persongroup fit. She concludes that a structured recruitment process improves the ability to identify job-relevant criteria, leading to the selection of better-qualified applicants.

In two Norwegian experimental studies (Bye et al. 2014; Horverak et al. 2013), managers' evaluation of immigrant job applicants are studied. They use the distinction between supplementary fit, that is, evaluating a candidate as fitting the organisational values, and complementary fit, that is, evaluating a candidate as different from the organisational culture but valuable to the organisation nonetheless (Horverak et al. 2013). The conclusion is that immigrant applicants who express a need to maintain their own minority culture are seen as having the lowest supplementary fit and are least hireable from the managers' perspective. Furthermore, the study shows that immigrant applicants who show an interest in participating in the majority culture but engage in the minority culture (integrated target), and those who express a need to adapt to the majority culture (the assimilated target) were more highly rated in complementary person-organisation fit. In a second study, Bye et al. (2014) show that, even if candidates are evaluated as having the same person-job fit, those having a low cultural fit are evaluated as less similar, less likable, less likely to perform well and likely to be a poor fit in the organisation.

Some studies stress the need for organisations to put in place recruitment and selection processes that find candidates who fit the organisation's needs and culture, irrespective of their ethnicity, sexuality, etc. This requires a more structured recruitment process that handles particular recruiters' biases (Boxall \& Purcell 2008; Robertson \& Smith 2001; Wolgast 2017).

There are some studies that focus on HR experts' perspectives of recruitment. Rynes et al. (2002) find that there are discrepancies between research findings and HR professionals' beliefs when it comes to the selection of candidates in the recruitment process. There are studies that examine HR experts' perspectives on different technologies used in the recruitment process (Chapman 2003; Thornburg 1998). However, all these studies, irrespective of what they examine, suggest that there is no perfect recruitment process for selecting candidates according to HR experts (Chapman 2003; Furnham 2008; Rivera 2012; Thornburg 1998).

In our review of previous research, there seems to be a focus on finding a candidate that fits the organisational culture through the recruitment process, or finding someone 
that can adapt to the majority culture - even when it comes to finding a candidate that is a complementary fit for the organisation. Organisational fit seems to be the final determinant of the recruitment process, and there seems to be a disadvantage for people that are seen as different from the majority culture. Research suggests that making the recruitment process more structured and related to person-job fit is a way to avoid the recruiter's personal biases in the recruitment process. At the same time, research also shows that many HR experts do not take into account research in their recruitment practices. Hence, it is important to explore HR experts' narratives of their practices, how they legitimate each practice and the dilemmas they encounter in this process. This research approach has not been previously tried to the best of our knowledge.

\section{Theoretical points of departure}

The concept of organisational recruitment practice includes the concepts of both recruitment and practice. 'Recruitment' is here defined as the process of analysing job requirements, attracting and selecting potential candidates, and introducing them to the workplace (Anell 2015). It is seen as a central process in HR work. 'Practice' refers to both what actors do and say, and to the 'nexus of doings and sayings' in specific situations in time and space (Buch et al. 2015). Czarniawska (2014) defines practice as ongoing processes of organising, where actors coordinate their actions in everyday life, and make sense of them retrospectively (Weick 1995). Recruitment practices are defined both in terms of what actors do when they work with recruitment processes in different situations, and how they narrate their ongoing work that is situated in these recruitment practices. From Czarniawska's (2014) perspective, narratives are seen as actions:

The everyday organizing consists of fragmented activities and events, apparently disjointed actions and conversations that seem to have no particular meaning. But it is just this hodgepodge of events, actions and talks that is the material for the later narratives, for stories that host heroes and villains, dramatic events and daring actions, full of significance for the storyteller if not always for the listener or the reader. (Czarinawska 2014, 33)

In this article, we distinguish between the logic of practice and the logic of representation when analysing organisational recruitment practices. The logic of practice is defined as concrete actions and narratives situated in time and space, discursively incomplete and tacitly oriented. The logic of representation means making sense of the ongoing practice and legitimate it as rational and making it acceptable in an institutional order.

When we use this distinction in our analysis, we capture the logic of practice by focusing on the HR experts' narratives of concrete examples of situations where they have acted in different stages of the recruitment process. The logic of representation is used to focus on how these narratives of the concrete situations are legitimated as rational or dilemmatic ways of recruiting. Thereby, we also describe the dilemmas regarding the recruitment of underrepresented groups, identified in the in relation to each practices retrospectively. 


\section{Method}

This article is based on a qualitative analysis of narratives from HR experts, which were collected through semi-structured interviews. The data collected and analysed in this paper are part of an ongoing research and developmental project financed by EU Erasmus, which aims to enhance the employability of nontraditional graduates after higher education (HE). Nontraditional graduates are defined as underrepresented groups in HE, such as students with low-educated parents, migrants, mature graduates and students with disabilities.

\section{Interviewees}

Narratives from 10 HR experts were collected through semi-structured interviews. The HR experts featured were chosen because of their extensive and varied experiences from $\mathrm{HR}$, working in a wide range of organisations and sectors (see Table 1).

Table I A description of the HR experts interviewed in the study

\begin{tabular}{|c|c|c|c|c|c|c|c|c|c|c|}
\hline HR Experts & $\mathbf{I}$ & 2 & 3 & 4 & 5 & 6 & 7 & 8 & 9 & 10 \\
\hline Age & 48 & 53 & 47 & 48 & 41 & 45 & 26 & 52 & 51 & 41 \\
\hline Gender & $\mathrm{F}$ & M & $F$ & $\mathrm{~F}$ & $F$ & M & $F$ & $F$ & $F$ & $F$ \\
\hline Edu level & $M$ & M & B & M & B & $\mathrm{B}(*)$ & B & B & $\mathrm{B}(*)$ & $M$ \\
\hline Yrs of HR exp. & $<20$ & $<20$ & $<20$ & $<20$ & $10-20$ & $<20$ & $>10$ & $<20$ & $<20$ & $10-20$ \\
\hline Diff. Org. exp. & 7 & I & I & 10 & 3 & 5 & I & 6 & I & । \\
\hline $\begin{array}{l}\text { Sector } \\
\text { experiences }\end{array}$ & $\begin{array}{l}\text { Priv } \\
\text { Public }\end{array}$ & Public & Third & $\begin{array}{l}\text { Priv } \\
\text { Public }\end{array}$ & Public & $\begin{array}{l}\text { Priv } \\
\text { Public } \\
\text { Third }\end{array}$ & Priv & $\begin{array}{l}\text { Public } \\
\text { Third }\end{array}$ & Priv & Third \\
\hline $\begin{array}{l}\text { Size of org. } \\
(\mathrm{SME}-<50 \text {, } \\
\text { Large }>5 \mathrm{I})\end{array}$ & $\begin{array}{l}\text { SME } \\
\text { Large }\end{array}$ & Large & SME & $\begin{array}{l}\text { SME } \\
\text { Large }\end{array}$ & Large & $\begin{array}{l}\text { SME } \\
\text { Large }\end{array}$ & Large & Large & SME & Large \\
\hline $\begin{array}{l}\text { Highest } \\
\text { position }\end{array}$ & HR Dir & HR Dir & $\begin{array}{l}\text { Chief } \\
\text { Secr }\end{array}$ & $\begin{array}{l}\text { Vice } \\
\text { Pres }\end{array}$ & HR Dir & CEO & HR Ass & HR Dir & CEO & $\begin{array}{l}\text { HR } \\
\text { Man. }\end{array}$ \\
\hline
\end{tabular}

(*) Not a fulfilled Bachelor's degree.

Table 1 shows that the HR experts are highly experienced of recruitment in different types of organisations and with different types of personnel. In the interviews, we did not explicitly ask them about their social and ethnic background. However, three of them talked about their own background in the interviews - one of them about coming from a family with low levels of formal education, one of them about having a nonSwedish background and one of them about how her parents migrated to Sweden with low levels of formal education. Altogether, the HR experts talked about their experiences of recruitment in 36 different organisations. 


\section{Interviews}

The interviews were conducted during the autumn 2015 to the spring 2016. We used semi-structured interview on their experiences of recruitment, how they described different recruitment situations and the steps through which the recruitment process was carried out. They were also asked about their experiences of recruiting people from underrepresented groups, specifically prompting age, ethnicity, social background, disability and gender. One also specifically mentioned people from the LGBT community. Finally, they were asked about how successful the recruitment processes were.

\section{Qualitative analysis}

From the transcriptions of the interviews, we identified narratives that described four different types of recruitment practice. In most cases, the HR experts had experiences of different ways of recruiting, which means that the same types of recruitment practices were found in more than one narrative.

The HR experts' narratives also mentioned their ways of legitimating different recruitment practices as well as different recruitment dilemmas. In the second step of the analysis, these constructions were identified in relation to the different recruitment practices. In the final step, the recruitment practices were analysed in relation to the theoretical concepts of practice and heir rationale for how they legitimated their ways of recruiting in their narratives.

\section{Limitations of the study}

The study data consist of narratives from $10 \mathrm{HR}$ experts with extensive experience in different organisations and sectors in the Swedish labour market. One limitation of our study is that it is based on interviews but tries to capture organisational practices. In any case, Czarniawska (2014) claims that it is hard for organisational researchers to capture underlying organisational processes and the reasons behind them through observation. Another limitation is that, from a saturation perspective, it could be argued that the number of HR experts is too low.

From the argument of saturation, Malterud et al. (2016) point to the importance of 'high information power'. A study with a high information power, according to them, has a narrow study aim, a high specificity of the sample, an applied theory, a strong dialogue between researcher and interviewee, and an in-depth analysis of the case. From this perspective, we argue that the $10 \mathrm{HR}$ experts combined give specificity to the study and, through their narratives, not only deep insights in the process of specific practices in general, but also have a deep understanding of recruitment of underrepresented groups.

\section{Findings}

In this section, the four identified types of recruitment practice are described from the HR experts' narratives: the informal, the pragmatic, the standardised and the strategic 
recruitment practices. The dilemmas expressed by HR experts in relation to these recruitment practices are also presented.

\section{The informal recruitment practice}

The HR experts mention their experiences from recruiting internally and/or informally. In practice, this means to actively look for someone within the company, and to use their social and/or professional network to obtain references. To have someone recommended is seen as a sign of mutual personal trust and commitment between the employer, the recommender and the employee. A person is employed or get a call back if he/she is recommended. Recommendation is 'a form of guarantee that the person concerned will "feel at home" in the organisation':

Informal contacts are decisive today when you apply for a job. If I get an informal reference on someone, then the candidate moves up in the pile (of applications).... that I know someone at another company somewhere and I call them and ask: how is this woman actually, if I get a good response, then I know. (HR Expert 10)

In some cases, we have recruited on recommendations; some have had extra work here during their studies. (HR Expert 3)

We have found people within the organisation, ..., they have been at other departments or ... at other parts of the organisation and we have felt they have the right competencies and profiles ... we take him or her into the department to develop. (HR Expert 2)

The informal recruiting practice, then, concerns internal recruiting, as well as recruiting people based on recommendations from people you know and trust.

\section{The pragmatic recruitment practice}

The pragmatic recruitment practice is, according to the HR experts, described as 'the sensible way' of recruiting. Candidates are found through advertising and selection is done mainly through interviews. Sometimes, many people from the organisations are involved, checking references and administering tests, which is something HR experts feel comfortable doing:

It is the need of the organisation that is important. If I get a vacancy in my staff, Camilla is quitting and she has been working with these issues and has these competencies, but what do we need now, do we need her or can we move the tasks and do it some other place, or are we going to change the profile to get what we need... I do not think we have anything else but good sense. (HR Expert 2)

According to the HR experts, the pragmatic recruitment practice creates a dilemma of balancing between recruiting someone to fit the organisational culture or recruiting for diversifying the organisation:

I think it is a difficult act of balance. On the one hand, you talk about values and the importance of fitting into an organisation and on the other hand you talk about diversity 
and you have to say that this is a contradiction. Then you have to be very clear with yourself. (HR Expert 1)

In other words, the challenge of pragmatic practices relates to convincing others to employ 'a different candidate' than the norm, and thus force the experts to deal with prejudice from others in the organisation. Recruiting only one 'different person' is also perceived as problematic. It puts the burden on the individual as a representative of a group. If the individual fails, which is possible, the enhancement of diversity also fails.

When you recruit... you choose someone that fits in the culture in the organisation and if there are too many that are the same, you have to think about it... you have to have a diversity perspective with you all the time, in parallel... just to say we have to few girls in the store house and recruit one poor girl, it does not work and if you than say that we have to recruit one more, then they say, she was not good enough, we don't want another one. (HR Expert 1)

The pragmatic practice is therefore seen as a balancing act between the current and future organisational cultures, as well as between the individual and the organisation. Hence, the risk of pragmatic recruitment practice is that it can result in a strategy of adaption, rather than developing or changing the organisational culture to recruit for diversity.

\title{
The standardised recruitment practice
}

According to the HR experts, standardised recruitment practice is perceived as a sequential process: organised and carried out by recruitment companies in accordance with a system for quality assurance. It is based on an analysis of job requirements, selection and to present potential candidates:

\begin{abstract}
Our recruitment process is certified, so we have firm routines for how a recruitment process is to be done... from taking in applications to having a candidate - several steps that we cannot abandon such as taking two references on each candidate, that candidates have to do the test as a first screening, which is supposed not to discriminate against a candidate from a personal point of view. That is why we sent out a test from different profiles, test profiles that we have created. Depending on what kind of position, it shows the results differently to us as recruiters, but the test is the same for everyone. (HR Expert 7)
\end{abstract}

The first stage of the recruitment process is to help the companies define the job requirements in detail. In this process, specific key competencies are specified (such as knowledge, intellectual skills, practical and personal skills) and personal profiles are required for the position, which are then used in searching for candidates. The selection of candidates is conducted in four steps. The first step includes testing all candidates through screening, where they are given a personality test based on identified personal profiles classified in the job analysis. In the second step, the CVs of those with the right profile are reviewed in accordance with the required key competencies. In the third step, two references are taken and the matched candidates are interviewed and presented to the 
company. According to the HR Experts, one advantage of the standardised recruitment processes is for the recruitment company to counteract discrimination:

...we work extensively with discussing ...discrimination and it is very up to date at our company all the time how we work with this... which I think is profoundly good. To be reminded of what is important when working with recruitment and to be close to customers means to run into others asking us to discriminate, so we have to stop it... it makes me proud to know that I do not recruit on age or gender or ethnicity or anything else... (HR Expert 7)

One critique, however, against the standardised recruitment practice is that it creates a picture of a stereotyped 'standard person' that matches the different stages in the recruitment process, who is not necessarily the best candidate for the job. Another critique is that the financial transaction between the recruitment company and the company requires a 'quick fix' rather than a serious process of finding the most suitable candidate. From the HR experts' perspective, the standardised recruitment practice seems to measure the competence for getting through the recruitment process, rather than focusing on the competence for the required job:

It has become much of a transaction because you turn directly to a recruitment company that can find someone and I know that the recruitment company wants a fast delivery so what I get back through the recruitment company is a bunch of standardised persons, a quick fix in all senses, which means... no one is happy... I think we are generally scared to be challenged by HR saying do you really want someone with a traditional background, what are the competencies you really look for? (HR Expert 4)

...recruitment processes are about measuring how good you are at taking yourself through the recruitment process and not how good you are at work, which is a huge problem and I do think that HR needs to take responsibility for identifying what competencies you really need in your work to be able to do it and organise the process in relation to that. You often have a standardised recruitment process... good you fit in the model but not in your work. (HR Expert 6)

However, though the practice guards against discrimination, it does not necessarily enhance diversity. According to the HR experts, experiences of bad analyses of job requirements, together with standardised recruitment processes, select 'standard people' who are good at going through the recruitment process itself, but not necessarily the ones needed at the workplace.

\section{The strategic recruitment practice}

Finally, most of the HR experts have experiences of working strategically to enhance diversity in an organisation. One strategy is to have a diversity policy and practice to recruit for diversity:

We work with three different colours... it is not about having a pride flag but it is about that everybody cannot be 33,5 years old, living in Täby (upper middle class area of Stockholm) 
and being raised there, having children and being married. We talk about that a lot that we do not want that. But it is a challenge and difficult as we have to deliver to customers as we are always selling. (HR Expert 8)

HR Expert 8, who has her own recruitment company, raises the dilemma that, even if they have a clear strategy for enhancing diversity, customers make the final decisions in the end. As they are dependent, they are not always able to practice their diversity strategy. The HR experts have the experience and ambition to change the values in the organisation, and to try to link the widening of access to the business or success of the organisation in general.

When I worked at company $C$ it was a challenging task with widening diversity, because if you looked at the company as a whole there was a good diversity concerning ethnicity, but the problem was that everyone worked in the production and in the storehouse. We looked closer and realised that our sales men, they were white, middle aged men between 30 and 40 and we said okay but are we going to ... recruit others because our customers have a different ethnical mix... we turned it around to see how it could enhance the business. (HR Expert 1)

When I worked in the security business ... we wanted to enhance diversity so we worked explicitly ... we wanted women and we explicitly worked with other ethnical groups and also with HBTQ and homosexual people, when you start it goes quite fast. ... It was a disappointment from our American owners, which made the whole thing a short exception that makes me disenchanted ... I quit, our manager was fired and every female manager quit. (HR Expert 4)

The narrative of the HR expert is that the explicit strategic recruitment practice was declined by the American owner and all the people involved were fired, which was a huge disappointment to her. Some of the HR experts have experience of recruiting to enhance diversity, as evidenced by the quotations above and below. From the narratives, it can be seen that it is problematic if different actors at different levels do not agree with the strategy.

Another problem that HR experts experience with strategic recruitment is finding the right people. In the military, for example, there is prejudice against the military itself, which makes it difficult to attract a diverse pool of potential candidates.

In the military service, we have had problems with reaching people born outside Europe because they do not apply through ordinary recruitment projects or through an advertisement in the paper, so we have tried to find other ways of reaching them .... I would have been happy to have someone with another cultural background as well, to be able to have these questions illuminated from another perspective as we are working internationally as well, it is important in my department and I miss it but I have not been able to find anyone... We learnt through a project that you need to go out in certain groups and discuss the role of the military service... sometimes it is also important to talk to parents because there are ways of looking at the military from their home countries that could be more or less problematic. In the civil organisation, the mix is a little better. (HR Expert 2) 
The HR experts stress that strategic recruitment practice is particularly effective for recruiting and enhancing the recruitment of certain groups. A dilemma, however, is that working strategically with changing recruitment practices is easy to initiate, but seems to lead to open conflicts in the organisation and they are thereby difficult to institutionalise as part of the organisation's recruitment practices. The strategy becomes temporary in nature, and does not lead to changes in the organisation's recruitment practices. Another dilemma is that it is difficult to find the right candidates when one focuses on a specific category.

\section{Summary}

In Table 2, the different recruitment practices are summarised.

Table 2 Recruitment practices, methods and experienced dilemmas

\begin{tabular}{|c|c|c|}
\hline $\begin{array}{l}\text { Recruitment } \\
\text { practices }\end{array}$ & Methods & Experienced dilemmas \\
\hline $\begin{array}{l}\text { The informal } \\
\text { recruitment practice }\end{array}$ & $\begin{array}{l}\text { Internal recruitment } \\
\text { Recruiting someone you know. } \\
\text { Recruitment from social contacts. }\end{array}$ & No mentioned dilemmas. \\
\hline $\begin{array}{l}\text { The pragmatic } \\
\text { recruitment practice }\end{array}$ & $\begin{array}{l}\text { Finding someone that suits the needs of } \\
\text { the company. } \\
\text { Using suitable techniques such as: } \\
\text { interviews, references, tests, and other } \\
\text { methods, depending on the situation. } \\
\text { Built on the recruiters' competence and } \\
\text { ethical considerations. }\end{array}$ & $\begin{array}{l}\text { Hard to balance between adapting } \\
\text { to, or developing, the organisational } \\
\text { culture. }\end{array}$ \\
\hline $\begin{array}{l}\text { The standardised } \\
\text { recruitment practice }\end{array}$ & $\begin{array}{l}\text { A deliberate standardised process in } \\
\text { five steps: } \\
\text { I. Analysing job requirements, identify- } \\
\text { ing key competencies and personal } \\
\text { profiles. } \\
\text { 2. Personality test in accordance with } \\
\text { personal profiles. } \\
\text { 3. CV review in accordance with key } \\
\text { competencies. } \\
\text { 4. References from two sources. } \\
\text { 5. Interviewing of candidates. }\end{array}$ & $\begin{array}{l}\text { Creates 'standard people' and there- } \\
\text { fore counteracting diversity. } \\
\text { Measures how good a person is at } \\
\text { going through the recruitment process, } \\
\text { not how good he/she is going to be } \\
\text { in work }\end{array}$ \\
\hline $\begin{array}{l}\text { The strategic recruit- } \\
\text { ment practice }\end{array}$ & $\begin{array}{l}\text { Working with changing organisational } \\
\text { values, recruiting certain groups for } \\
\text { change. } \\
\text { Finding new ways of finding and attract- } \\
\text { ing candidates. }\end{array}$ & $\begin{array}{l}\text { Creates conflicts of interest between } \\
\text { actors in organisations. } \\
\text { Temporary changes in recruitment } \\
\text { practices and organisations. } \\
\text { Hard to find the right person in accor- } \\
\text { dance with the prioritised categories } \\
\text { of people. }\end{array}$ \\
\hline
\end{tabular}

Table 2 shows the different methods used in different recruitment practices and the experienced dilemmas of each practice as narrated by HR experts. 


\section{Discussion}

The aim of this article is to explore organisational recruitment practices from HR experts' narratives and discuss the challenges in recruiting underrepresented groups in relation to these practices.

In the analysis, we identify four organisational recruitment practices: the informal, the pragmatic, the standardised and the strategic. Even if these practices show different ways of recruiting, most of the HR experts have similar experiences of all of them. In other words, it shows that they have a shared way of acting in relation to the practice of recruitment in general (see Buch et al., 2015).

Departing from Czarniawska's (2014) conception of organisational practices as both the logic of practice and the logic of representation, the narratives of the HR experts and their different ways of recruiting seem to have different rationalities. In Table 3, we present the recruitment practices in relation to the different rationalities that legitimate each practice.

Table 3 The recruitment practices in relation to the rationality that legitimates each practice

\begin{tabular}{|c|c|}
\hline $\begin{array}{l}\text { The different } \\
\text { recruitment practices }\end{array}$ & The rationality of the practices \\
\hline $\begin{array}{l}\text { The informal recruitment } \\
\text { practice }\end{array}$ & $\begin{array}{l}\text { The rationality of strengthening the psychological contract and mutual } \\
\text { commitment between organisation and employee. } \\
\text { Built on 'subjective criteria' from the recruiters' personal and social } \\
\text { networks. }\end{array}$ \\
\hline $\begin{array}{l}\text { The pragmatic recruitment } \\
\text { practice }\end{array}$ & $\begin{array}{l}\text { The rationality of the 'sensible way' of balancing the need to adjust to and } \\
\text { develop the organisation. } \\
\text { Built on 'subjective criteria' from the recruiters' experiences, competence } \\
\text { and ethical considerations. }\end{array}$ \\
\hline $\begin{array}{l}\text { The standardised } \\
\text { recruitment practice }\end{array}$ & $\begin{array}{l}\text { The rationality of counteracting discrimination. } \\
\text { Built on 'objective' measures in relation to key competencies and } \\
\text { standardised criteria. }\end{array}$ \\
\hline $\begin{array}{l}\text { The strategic recruitment } \\
\text { practice }\end{array}$ & $\begin{array}{l}\text { The rationality of a radical way to enhance diversity. } \\
\text { Built on strategies and actions towards specific target groups. }\end{array}$ \\
\hline
\end{tabular}

The informal and pragmatic recruitment practices are built on 'subjective judgements' from the recruiters' experiences, competencies, ethical considerations and personal networks. The practices are also mostly legitimated through a person-organisation fit (Sekiguchi \& Huber 2011). The informal recruitment practice is legitimated by creating a psychological contract and a mutual commitment between the organisation and employee through the personal contact between the recruiter and the recruit. Despite this, the HR experts do not experience any dilemmas with the informal recruitment practice.

The pragmatic recruitment practice is legitimated as the 'sensible way' of recruiting, as it tries to adjust the process to a specific position, situation and organisation. The logic of the pragmatic practice is related to the person-organisation and person-group fit and tries to balance a supplementary fit with a complementary fit (Bye et al. 2014; Horverak et al. 2013; Venkatesh et al. 2017). 
The standardised recruitment practice is seen as rational, as it minimises the recruiters' own subjective experiences, competencies and biases in the process, as the practice is carried out with objective measures. It is related to the person-job fit, which, as Wolgast (2017) suggests, is the best way to enhance diversity in organisations, which is an argument the HR experts also use as a legitimating criterion. However, many of the HR experts highlight dilemmas with the standardised recruitment practice, as it does not always measure the best person-job fit, but rather the competencies for going through the recruitment process.

The strategic practice is, from the HR experts' perspective, a radical way to enhance diversity, and targets prioritised groups that are sometimes underrepresented. It relates to the complementary fit, as it is based on the idea that the organisation will gain value from a diverse workforce (Bye et al. 2014). The HR experts identify several conflicts that have consequences for both the organisation and recruited individuals.

How can we understand the challenges of different recruitment practices in increasing the recruitment of underrepresented groups in the labour market more generally? In the Introduction, we defined recruitment as the process of finding people with the right skills for the right positions, irrespective of their origin (Bolander 2002; Breaugh 2000, 2008; Skorstad 2011). In previous research, we found support for a more standardised process of recruitment, with a focus on person-job fit as the best way to increase the recruitment of underrepresented groups (Wolgast 2017). From the results of this study, we are not sure.

The standardised practice, on the one hand, uses 'objective' measures to select the most qualified person from a pool of applicants, irrespective of their ethnicity/race, sexuality, gender, etc., and is regarded as a way to counteract discrimination (compare Boxall \& Purcell 2008; Robertson \& Smith 2001; Wolgast 2017). On the other hand, and from the HR experts' perspective, there seems to be a risk that this process can lead to the recruitment of 'standard' persons and thereby becomes a way to prevent diversity.

From our results, as noted earlier, we argue that the informal recruitment practice can be seen as the most exclusionary in relation to minorities, as it builds on personal contacts and networks. However, it depends on the social networks that are available to the HR expert and the employees of the organisation.

The strategic recruitment practice can be seen as the most discriminatory. It is a radical approach for enhancing diversity. Targeting a specific group can, as this article shows, lead to conflicts between different actors with different values, and it requires extended strategic work and diversity management in the organisation to be able to work (Pitts 2009).

The pragmatic recruitment practice is a challenging balancing act, where the HR expert makes a judgement as to whether a potential candidate can 'fit in' and be accepted by colleagues in the organisation. A risk here is that the most competent is not always selected in this process.

The conclusion of this article is that there seems to be a paradox between counteracting discrimination and enhancing diversity; recruitment practices that counteract discrimination do not necessarily enhance diversity, and recruitment practices that work to increase diversity could be seen as discriminatory. One might well ask if there exists an effective recruitment practice for the recruitment of underrepresented groups in the labour market; from this study, the answer is no.

The result of this study supports previous research, where HR experts did not find a good method for such recruitment (Chapman 2003; Gilbert \& Ivanevich 2000; Rivera 
2012). It could also be argued that the legitimacy of the practices could be related to HR experts beliefs based on their own experiences, rather than beliefs supported by research (Rynes et al. 2002). From the HR experts' narratives, however, the organisation, its management and culture are sometimes seen as a dilemma for recruiting underrepresented groups. From this perspective, it seems important to broaden the perspective of recruitment to also include diversity management, which values an inclusive organisational culture. More research is needed about recruitment practices and their impact on the social inclusion of minorities in the labour market generally.

\section{References}

Anell, S. (2015). Hållbar polisrekrytering: teoretiska, metodologiska och praktiska perspektiv pà rekrytering och urval [Sustainable police recruitment: theoretical, methodological and practical perspective on recruitment and selection], Stockholm: Psykologiska institutionen, Stockholms universitet.

Baert, S., Cockx, B., Gheyle, N \& Vandamme, C. (2015). Is there less discrimination in occupations where recruitment is difficult? ILR Review 68(3): 467-500. Doi: https://doi. org/10.1177/0019793915570873.

Bergström, O. 1998. Att passa in: rekryteringsarbete i ett kunskapsintensivt företag [To fit in: recruitment work in a knowledge-intensive company], Göterborg: Bas förlag.

Blommaert, L., Coenders, M. \& van Tuberger, F. (2014). Discrimination of Arabic-named applicants in the Netherlands: an internet-based field experience examining different phases in online recruitment procedures, Social Forces 92(3): 957-982.

Bolander, P. (2002). Anställningsbilder och rekryteringsbeslut [Employment and recruitment decision]. Stockholm: Doktorsavhandling (Dissertation), Handelshögskolan i Stockholm (Stockholm School of Economics), Programmet Människa och Organisation (PMO).

Boxall, P., \& Purcell, J. (2008). Strategy and Human Resource Management, Bristol, Palgrave.

Breaugh, J. A. \& Starke, M. (2000). Research on employee recruitment: so many studies, so many remaining of, Management 26(3): 405-434. Doi: https://doi.org/10.1177/ 014920630002600303 .

Breaugh, J. A. (2008). Employee recruitment: current knowledge and important areas for future research, Human Resource Management Review 18: 103-118. Doi: https://doi. org/10.1016/j.hrmr.2008.07.003.

Brower, T. \& Caven, V. (2013). Performance, gender and sexualised work: Beyond management control, beyond legislation \& quest: a case study of work in a recruitment company, Equality, Diversity and Inclusion: An International Journal 32(5): 475-490. Doi: https:// doi.org/10.1108/EDI-08-2011-0051.

Buch, A., Andersen V. \& Klemsdal, L. (2015). Turn to practice within working life studies, Nordic Journal of Working Life Studies 5: 1-11. Doi: https://doi.org/10.19154/njwls. v5i3a.4830.

Bursell, M. (2007). What's in a name? A field experiment test for the existence of ethnic discrimination in the hiring process, Stockholm: Working Paper 2007: 7. The Stockholm University Linnaeus Center for Integration Studies (SULCIS).

Bye Høivik, H., Horverak Gytre, J., Sandal Mjeldheim, G., \& Sam Lackland, D. (2014). Cultural fit and ethnic background in the job, International Journal of Cross Cultural Management 14(1): 7-26. Doi: https://doi.org/10.1177/1470595813491237.

Chapman, D. S., \& Webster, J. (2003). The use of technologies in the recruiting, screening, and selection processes for job candidates, International Journal of Selection and Assessment, 11(2-3): 113-120. Doi: https://doi.org/10.1111/1468-2389.00234. 
Czarniawska, B. (2014). The Theory of Organizing, Second Edition, Cheltenham: Edward.

Derous, E., Nguyen, H. \& Ryan, A. M. 2009. Hiring discrimination against Arab minorities: interactions between prejudice and job characteristics, Human Performance 22(4): 297-320. Doi: https://doi.org/10.1080/08959280903120261.

D’Netto, B \& Sohal, A S. (1999). Human resource practices and workforce diversity: an empirical assessment, International Journal of Manpower 20(8): 530-547. Doi: https://doi. org $/ 10.1108 / 01437729910302723$.

Eriksson, S. \& Lagerström, J. (2012). Detecting discrimination in the hiring process: evidence from an Internet-based search channel, Empirical Economics 43(2): 537-563. Doi: https://doi.org/ 10.1007/s00181-011-0496-6.

Fernandez, R M. \& Campero, S. (2017). Gender sorting and the glass ceiling in high-tech firms, ILR Review 70(1): 73-104. Doi: https://doi.org/10.1177/0019793916668875.

Furnham, A. (2008). HR professionals' beliefs about, and knowledge of, assessment techniques and psychometric tests, International Journal of Selection and Assessment 16(3): 300-305. Doi: https://doi.org/10.1111/j.1468-2389.2008.00436.x.

Gilbert, J. A., \& Ivancevich, J. M. (2000). Valuing diversity: a tale of two organizations, Academy of Management Perspectives 14(1): 93-105. Doi: https://doi.org/10.5465/ ame.2000.2909842.

Hoque, K. and Noon, M. (1999). Racial discrimination in speculative applications: new optimism six years on? Human Resource Management Journal 9(3): 71-82. Doi: https://doi. org/10.1111/j.1748-8583.1999.tb00204.x.

Horverak Gytre, J, Bye Høivik, H., Sandal Mjeldheim, G. \& Pallesen, S. (2013). Managers' evaluations of immigrant job applicants: the influence of acculturation strategy on perceived person-organization fit (P-O Fit) and hiring outcome, Journal of Cross-Cultural Psychology 44(1): 46-60. Doi: https://doi.org/10.1177/0022022111430256.

Kaplan, D. \& Fischer, J. (2009). A rose by any other name: identity and impression management in résumes, Employee Responsibilities \& Rights Journal 21(4): 319-332. Doi: https://doi.org/10.1007/s10672-009-9127-1.

Malterud, K., Siersma1, V. D. \& Dorrit, A. (2016). Sample size in qualitative interview studies: guided by information power., Qualitative Health Research 26(13): 1753-1760. Doi: https://doi.org/10.1177/1049732315617444.

Mamaril, N. \& Royal K. D. Women and minorities in engineering: a review of literature. Paper presented at the 2008 Mid-western Educational Research Association, Columbus.

McGinnity, F. \& Lunn, P. D. (2011). Measuring discrimination facing ethic minority job applicants: an Irish experiment, Work, Employment \& Society 25(4): 693-708. Doi: https:// doi.org/10.1177/0950017011419722.

Mckay, P. F. \& Avery, D. R. (2005). Warning! Diversity recruitment could backfire, Journal of Managerial Issue (14): 330-336. Doi: https://doi.org/10.1177/1056492605280239.

Osman, A. (2012). In search of green pastures: the onward immigration of Somali-Swedes to Britain, Nordic Journal of Immigration 2(2): 133-140. Doi: https://doi.org/ 10.2478/ v10202-011-0035-8.

Pitts, D. (2009). Diversity Management, job satisfaction, and performance: evidence from U.S. federal agencies, Public Administration Review, 69(2): 328-338. Doi: http://www. jstor.org/stable/27697867.

Poulston, J., \& Jenkins, A. (2016). Barriers to employment of older hotel workers in New Zealand, Journal of Human Resources in Hospitality \& Tourism 15(1): 45-68. Doi: https://doi.org/10.1080/15332845.2015.1041003.

Rivera, L. A. (2012). Hiring as cultural matching: the case of elite professional service firms, American Sociological Review 77(6): 999-1022. Doi: https://doi.org/10.1177/ 0003122412463213.

Robertson, T. \& Smith, M. (2001). 'Personnel selection, Journal of Occupational and Organisational Psychology 74(4): 441-472. Doi: https://doi.org/10.1348/096317901167479. 
Rynes, S. L., Colbert, A. E., \& Brown, K. G. (2002). HR professionals' beliefs about effective human resource practices: correspondence between research and practice, Human Resource Management, 41(2): 149-174. Doi: https://doi.org/10.1002/hrm.10029.

Sargeant, M. (2010). Young Workers and Age Discrimination. International Journal of Comparative Labour Law \& Industrial Relations, 26(4): 467-478.

Sekiguchi, T. \& Huber, V. L. (2011). The use of person-organisation fit and person-job fit information in making selection decisions, Organisational Behaviour \& Human Decision Processes 116(2): 203-216. Doi: https://doi.org/10.1016/j.obhdp.2011.04.001.

Skorstad, E. (2011). Rätt person på rätt plats: psykologiska metoder för rekrytering och lederskapsutveckling [Right person in the right place: psychological methods for recruitment and leadership development], Lund: Studentlitteratur.

Stevanovic, B. (2014). Recruitment and workplace integration of men and women engineers in France: the case of EPF Ecole D'ingénieurs graduates, Journal of Education and Work 27(3): 243-264. Doi: https://doi.org/10.1080/13639080.2012.728285.

Thornburg, L. (1998). Computers-assisted interviewing shortens hiring cycle, HR Magazine 43: 73-79.

Tovatt, C. (2013). Erkännandets Janusansikte - Det sociala kapitalets betydelse i arbetslivskarriärer (Janus face of recognition - The importance of social capital in working life careers), Stockholm: Santérus.

Venkatesh, V., Windeler, J. B., Bartol, K. M, Williamson, I. O. (2017). Person-organization and person-job-fit. Perceptions of new IT employees: work outcomes and gender differences, MIS Quaterly 41(2): 525-558. Doi: https://doi.org/10.25300/misq/2017/41.2.09.

Verniers, C. \& Vala, J. (2018). Justifying gender discrimination in the workplace: the mediating role of motherhood myths, PLoS One 13(1): 1-23. Doi: https://doi.org/10.1371/ journal.pone.0201150.

Vesterberg, V. (2015). Learning to be Swedish: governing migrants in labour-market projects, Studies in Continuing Education 37(3): 302-316.

Weick K. (1995). Sense-making in Organizations, Thousand Oaks: Sage.

Wolgast, S. (2017). How Does the Job Applicants' Ethnicity Affect the Selection Process? Norms, Prefered Competencies and Expected Fit, Lund: Psykologiska institutionen. Lunds universitet. 